\title{
EFFECT OF PARAMETERS OF WELDING CIRCUIT ON FORMATION OF WELDING CURRENT PULSES
}

\author{
G.A. TSYBULKIN \\ E.O. Paton Electric Welding Institute, NASU \\ 11 Kazimir Malevich Str., 03680, Kiev, Ukraine. E-mail: office@paton.kiev.ua
}

\begin{abstract}
This work studies a poorly investigated effect of welding arc parameters on amplitude of welding current pulses in consumable electrode gas-shielded pulsed arc welding (PAW). A welding circuit is considered as a frequency-selective system, which passes the pulses in undistorted form only in specific frequency band. The pulses out of this band are significantly suppressed, that can result in rapid decrease of PAW efficiency. The main aim of the work is to determine a width of welding circuit pass band and possibility of its increase. In scope of developed mathematical model a criterion was obtained, which sets in algebraic form one of the necessary conditions of PAW efficient application. From practical point of view, this criterion allows, using known parameters of welding circuit, carrying out a fairly simple evaluation of pass band upper boundary, inside which a set amplitude of welding current pulses is ensured. From the other side, indicated criterion can be used for solving an inverse problem, i.e. to determine the allowable values of some parameters of welding circuit using preliminary selected frequency of welding current pulse passing. Besides, due to its «analytical property» the indicated criterion can be useful for theoretical investigations of pulse-arc processes taking place in the welding circuit. 19 Ref., 5 Figures.
\end{abstract}

Keyw ord s: pulsed arc welding, consumable electrode, welding circuit, welding current amplitude, pulse repetition frequency, mathematical model

One of the most efficient welding technologies, developed back in the 1960s and received further propagation in our country and abroad [1-15], is a consumable electrode gas-shielded pulsed arc welding (PAW). The rising interest to its application in the last time is to large extent related with robotization of arc welding and coming into industry of improved welding equipment, including the sources of pulsed welding current. These sources are characterized by new possibilities in welding mode regulation and, in particular, possibility of program setting of current amplitude in the pulse, pulse duration, background current and pulse setting frequency. It is well known fact that the optimum transfer of electrode metal during PAW is achieved at specific combination of indicated parameters.

A lot of publications were dedicated to the problems of stabilizing, adaptive regulation and practical realization of PAW $[4,6,8,9]$. But, at the same time, particularly important question, related with effect of welding circuit parameters on formation of the pulses of welding current, have almost no description in the reference literature. The matter is that the welding circuit in dynamic relationship represents itself a frequency-selective system which passes the undistorted pulses only in specific frequency band [12]. Out of this band the pulses will be significantly suppressed, that can result in rapid decrease of PAW efficiency.

(c) G.A. TSYBULKIN, 2016
Meanwhile, it is difficult to say what the width of indicated frequency band is and how it depends on welding circuit parameters and what are the possibilities of its expansion. The answer on these questions is very important from practical point of view, since they can provide clear vision on real frequency limitations, caused by dynamic properties of the welding circuit, which have to be taken into account in development of pulsed welding technologies and corresponding equipment. This paper is dedicated to solution of these issues.

Mathematical model. We study the scheme of welding circuit, given in Figure 1. The dynamic processes, taking place in it, obey the equations

$$
\left.\begin{array}{c}
\left(L_{1}+L_{2}\right) \frac{d i}{d t}+\left(R_{1}+R_{2}\right) i=u_{\mathrm{s}}(t)-u_{\mathrm{a}}(i, l), \\
u_{\mathrm{a}}(i, l)=u_{0}+E l+S_{\mathrm{a}} i, \\
l=H-h, \\
h=h_{0}+v_{\mathrm{e}} t-M \int_{0}^{t} i d t .
\end{array}\right\}
$$

The following designations are taken in these equations and in Figure 1, namely $i=i(t)$ is the welding current; $L_{1}, R_{1}, u_{\mathrm{s}}(t)$ are the inductance, internal resistance and pulse voltage of welding current source (WCS); $L_{2}$ is the inductance of welding circuit, formed by supply leads; $R_{2}$ is the sum resistance of electrode stick-out, supply leads and sliding contact in a nozzle tip; $u_{\mathrm{a}}=u_{\mathrm{a}}(l, t)$ is the arc voltage; $u_{0}$ is the sum of near electrode voltage drops; $l=l(t)$ is the arc length; 


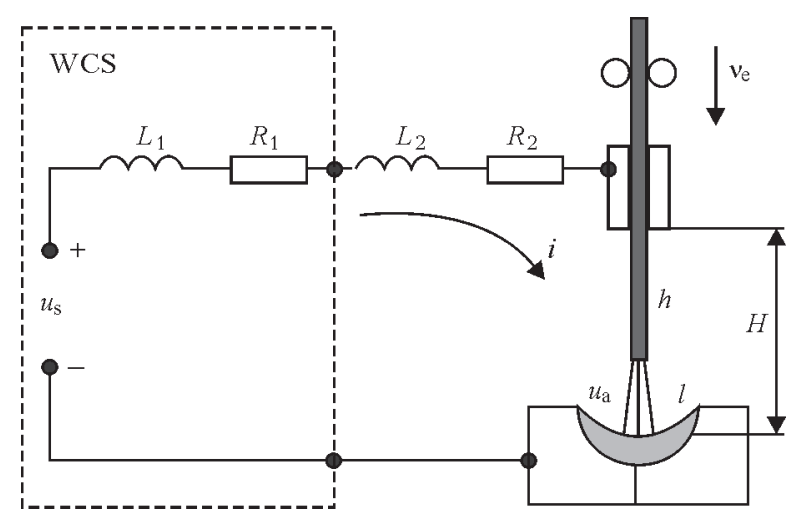

Figure 1. General scheme of welding circuit (for designations see the text)

$S_{\mathrm{a}}=\partial u_{\mathrm{a}} / d i$ is the arc volt-ampere slope; $E=\partial u_{\mathrm{a}} / \partial l$ is the intensity of electric field in the arc column; $H$ is the distance between the end of current conducting tip and free surface of weld pool; $h_{0}$ and $h=h(t)$ are the initial and current value of electrode stick-out; $v_{\mathrm{e}}$ is the electrode feed rate; $M=\partial v_{\mathrm{m}} / \partial i$ is the current slope of electrode melting; $v_{\mathrm{m}}=v_{\mathrm{m}}(t)$ is the rate of electrode melting; $t$ is the current time.

Eliminating the variables $u_{a}(l, t), l(t)$ and $h(t)$ from equation system (1) and assuming that $v_{\mathrm{e}}=$ const and $H=$ const, one of differential equation is received:

$$
L_{*} \frac{d^{2} i}{d t^{2}}+R_{\mathrm{w}} \frac{d i}{d t}+E M i=E v_{\mathrm{e}}+\frac{d u_{\mathrm{s}}}{d t},
$$

in which $L_{*}=L_{1}+L_{2}, R_{\mathrm{w}}=R_{1}+R_{2}+S_{\mathrm{a}}$.

Equation (2) is the simplified mathematical model of welding circuit. It was assumed during its design that possible fluctuations of $R_{\mathrm{w}}$ and $E$ parameters in process of arc welding are insignificant in comparison with variation of variables $u_{\mathrm{s}}(t)$ and $i(t)$ and it is no need in their consideration. Besides, such called small parameters [16] were not also taken into account, since their effect in solution of this problem can also be neglected.

Equation (2) is written in operative form

$$
\left(L_{*} p^{2}+R_{\mathrm{w}} p+E M\right) i=E v_{\mathrm{e}}+p u_{\mathrm{s}} .
$$

and for clarity this equation is compared with structural scheme, given in Figure 2.

In this scheme

$$
\begin{aligned}
& W_{1}=W_{1}(p)=\frac{E}{L_{*} p^{2}+R_{\mathrm{w}} p+E M}, \\
& W_{2}=W_{2}(p)=\frac{p}{L_{*} p^{2}+R_{\mathrm{w}} p+E M}
\end{aligned}
$$

are the transfer function from inputs $v_{\mathrm{e}}$ and $u_{\mathrm{s}}$ to output $i$ ( $p$ is the Laplace operator). From the scheme and expressions (3), (4) it is seen that the welding circuit in structural relationship is represented in form of sum of two elementary units, the first of which corresponds to basic frequency filter, and the second to band filter [17].

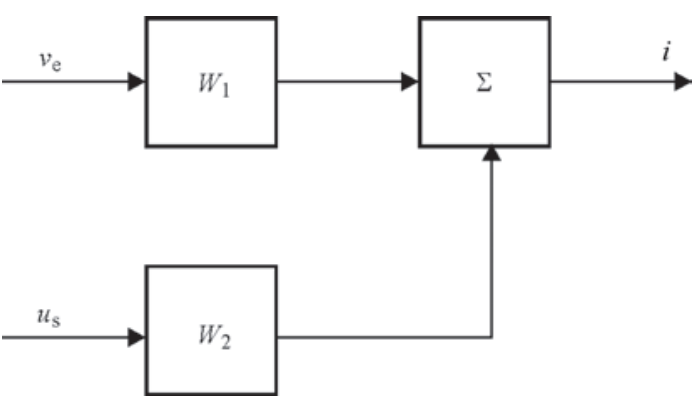

Figure 2. Structural diagram of welding circuit

The input action of unit $W_{1}$ is a rate of electrode wire feed $v_{\mathrm{e}}$, which is constant in our case. Stationary reaction $W_{1}$ according to (3) will also be constant and equal $i_{\infty}(t)=v_{\mathrm{e}} / M$. The input of unit $W_{2}$ receives action $u_{s}(t)$ in form of sequence of rectangular pulses. The amplitude of pulses at output $W_{2}$ in this case equal the amplitude of input pulses, multiplied by a value of frequency response characteristic (FRC) $A_{2}(\omega)=$ $=\mid W_{2}(j \omega)$, where $j=\sqrt{-1}, \omega=2 \pi f$, and $f$ is the frequency of pulse passing.

Thus, for evaluation of reaction of welding current on the action, being a periodic time function $u_{s}(t)$, it is necessary to have FRC of this circuit. It can be built using formula

$$
A_{2}(\omega)=\frac{\omega}{\sqrt{\left(E M-L_{*} \omega^{2}\right)^{2}+R_{\mathrm{w}}^{2} \omega^{2}}},
$$

which is developed after substitution in the expression (4) of imaginary variable $j \omega$ instead of operator $p$ [18].

Figure 3 shows a diagram of FRC of unit $W_{2}$. The same Figure includes a horizontal dashed line at the level of $\max A_{2} / \sqrt{2}$ that corresponds $-3 \mathrm{~dB}$ value.

Cross points of this line with the diagram $A_{2}(\omega)$ set the pass band $\Delta \omega=\omega_{2}-\omega_{1}$ of welding circuit. Obviously, the wider $\Delta \omega$ is, the higher frequency of pulse passing $f=\omega / 2 \pi$ can be used for performance of PAW with set amplitude of these pulses.

Let's consider what are the real possibilities of expansion of band $\Delta \omega$ exist. Analysis of expression

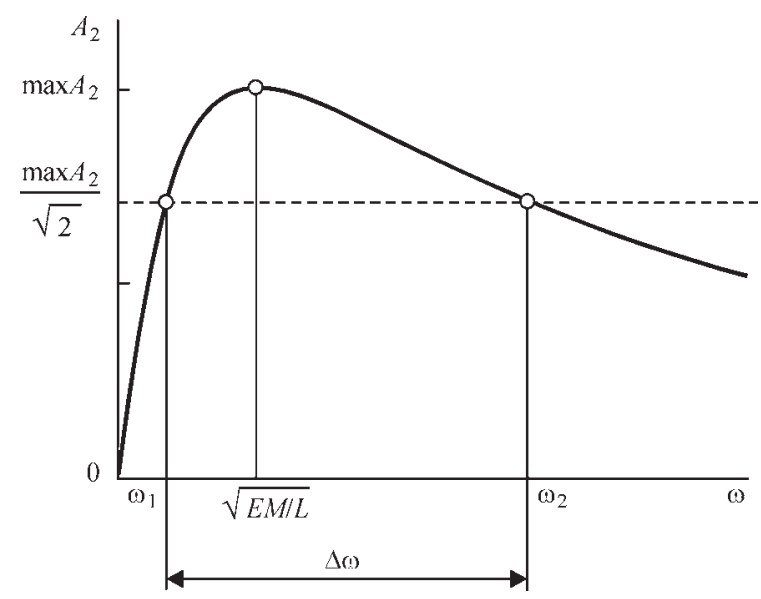

Figure 3. FRC of band filter $W_{2}$ 


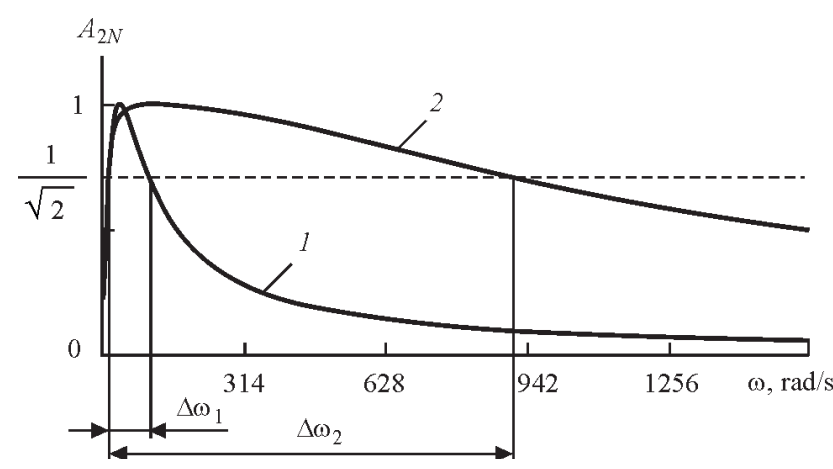

Figure 4. Normalized FRC of $\mathrm{W}_{2}$ unit (descriptions of curves 1, 2 see in the text)

(5) shows that parameters $R_{\mathrm{w}}$ and $L_{*}$, included in this expression, in contrast to $E$ and $M$, can be used for expansion of band $\Delta \omega$. Obviously, that sum resistance $R_{\mathrm{w}}=+R_{1}+R_{2}+S_{\mathrm{a}}$ can be changed only due to change of basic summand $R_{1}$, which sets an inclination of volt-ampere characteristic of WCS. However, this characteristic can be varied randomly. Another situation is with welding circuit inductance $L_{*}$. Its variation is allowed, as is well known, in sufficiently wide range without significant deterioration of welding itself [19].

Thus, practically, it is only one possibility for significant expansion of $\Delta \omega$, namely reduction of welding circuit inductance $L_{*}$. In order to show this possibility let's plot normalized FRS (Figure 4):

$$
A_{2 N}(\omega)=\frac{A_{2}(\omega)}{\max A_{2}(\omega)}=\frac{R_{*} \omega}{\sqrt{\left(E M-L_{*} \omega^{2}\right)^{2}+R_{\mathrm{w}}^{2} \omega^{2}}}
$$

for two different cases: when $L_{*}=0.5$ and when $L_{*}=$ $=0.05 \mathrm{mH}$. The values of other parameters of welding circuit, included in formula (6), are typical: $E=2 \mathrm{~V} /$ $\mathrm{mm}, M=0.31 \mathrm{~mm} /(\mathrm{A} \cdot \mathrm{s})$ and $R_{\mathrm{w}}=0.045 \mathrm{Ohm}$ (these values are taken from work [16]). From Figure 4 it can be seen that in the first case the pass band of welding circuit $\Delta \omega_{1}$ is sufficiently narrow: $\Delta \omega_{1}=91 \mathrm{rad} / \mathrm{s}$ (that corresponds to $\Delta f_{1}=14.5 \mathrm{~Hz}$ ). In the second case, the frequency band is significantly wider: $\Delta \omega_{2}=911 \mathrm{rad} / \mathrm{s}$ or $\Delta f_{2}=145 \mathrm{~Hz}$. Obviously that further reduction of inductance $L_{*}$ will result in more expansion of the welding circuit frequency band.

Naturally, there is a question, whether it is possible to find a dependence of pass frequency of welding current pulses $f$ directly on inductance $L_{*}$ in analytical form without using FRC graphical plotting. Let's consider equation $A_{2 N} /(\omega)=1 / \sqrt{2}$, which taking into account (6), is written in the following way:

$$
\frac{R_{\mathrm{w}} \omega}{\sqrt{\left(E M-L_{*} \omega^{2}\right)^{2}+R_{\mathrm{w}}^{2} \omega^{2}}}=\frac{1}{\sqrt{2}} .
$$

This equation is divided for two quadratic equations:

$$
\begin{aligned}
& L_{*} \omega^{2}+R_{\mathrm{w}} \omega-E M=0 \text { if } \omega<\sqrt{\frac{E M}{L_{*}}}, \\
& L_{*} \omega^{2}-R_{\mathrm{w}} \omega-E M=0 \text { if } \omega>\sqrt{\frac{E M}{L_{*}}} .
\end{aligned}
$$

Since we are interested in the upper boundary of pass band $\omega_{2}$ (see Figure 3), i.e. the case, when $\omega>\sqrt{E M / L_{*}}$, then only the second from given equations is considered. The following solution satisfies this equation:

$$
\omega_{2}=\frac{R_{\mathrm{w}}}{2 L_{*}}\left(1+\sqrt{1+\frac{4 L_{*} E M}{R_{\mathrm{w}}^{2}}}\right) .
$$

Taking into account that in the most of practical cases in PAW

$$
L_{*}<<\frac{R_{\mathrm{w}}^{2}}{4 E M},
$$

expression (7) is significantly simplified and takes the form of

$$
\omega_{2} \approx \frac{R_{\mathrm{w}}}{L_{*}}
$$

or (taking into account that $\omega_{2}=2 \pi f_{2}$ )

$$
f_{2} \approx \frac{R_{\mathrm{w}}}{2 \pi L_{*}} \text {. }
$$

Thus, if condition $f<f_{2}$ is fulfilled, namely if

$$
f<\frac{R_{\mathrm{w}}}{2 \pi L_{*}},
$$

then the pass frequency of welding circuit pulses $f$ is within the limits of the welding circuit pass band. This means that decrease of amplitude of the pulses in this case will not exceed a set margin $\triangle A=3 \mathrm{~dB}$.

Therefore, inequation (9) can be considered as one of the necessary conditions of efficient PAW application. This inequation due to its simplicity is very convenient for preliminary calculation of $f$. It is also wonderful that it due to its "analytical form» can be useful at theoretical investigations of pulse-arc processes taking place in welding circuit.

Results of calculation experiment. A calculation experiment was carried out in scope of mathematical model (2) in order to check an effect of inductance $L_{*}$ on amplitude of welding current pulses. The same parameters that were used in FRS plotting were used at that. Besides, the parameters of mode of robotized PAW were set, namely $v_{\mathrm{e}}=22 \mathrm{~mm} / \mathrm{s}, H=17 \mathrm{~mm}$, pulse duration $\tau=0.004 \mathrm{~s}, u_{\mathrm{s}}(t)=(30+10 z(t)) \mathrm{V}$, where

$$
\begin{gathered}
z(t)=\left\{\begin{array}{l}
1, \quad n T \leq t \leq(n T+\tau), \\
0, \quad(n T+\tau)<t<(n+1) T,
\end{array}\right. \\
T=1 / f, \quad n=0,1,2,3, \ldots .
\end{gathered}
$$

The frequency of pulse passing was taken equal $f=25 \mathrm{pulse} / \mathrm{s}$. This choice was made is such a way 
that its value was inside the pass band $\Delta f_{2} \approx 145 \mathrm{~Hz}$ $\left(\Delta \omega_{2}==911 \mathrm{rad} / \mathrm{s}\right)$, but, at the same time (see Figure $4)$, out of pass band $\Delta f_{2} \approx 14.5 \mathrm{~Hz}\left(\Delta \omega_{1}=91 \mathrm{rad} / \mathrm{s}\right)$.

The results of experiment are presented in Figure 5 in form of reaction of welding current $i(t)$ on effect of $v_{\mathrm{e}}=$ const and series of rectangular pulses $u_{\mathrm{s}}(t)$.

Comparison of this results shows that the pulses of welding current at $L_{*}^{\prime}=0.05 \mathrm{mH}$ (Figure 5,a) have sufficiently large amplitude. It can be explained by the fact that $f<f_{2}$ and welding circuit as a band-pass filter do not have in this case significant effect on pulse amplitude. At $L_{*}^{\prime \prime}=0.5 \mathrm{mH}$ the welding current pulses (Figure 5, $b$ ), as it was predicted, are significantly suppressed by welding circuit since $f>f_{2}$ in this case.

\section{Conclusions}

Carried investigation shows that the parameters of welding circuit, in particular, inductance $L_{*}$, have significant effect on characteristics of the welding current pulses. Effect of inductance $L_{*}$ on rate of increase and rate of reduction of welding current in the pulse is well known to the specialists dealing with PAW problems. However, up to the moment the level of its effect on amplitude of these pulses was not clear. It is shown as a result that the welding circuit as a dynamic system is characterized by specific pass band of the welding current pulses. If pulse passing frequency is out of the limits of this band, the amplitude of pulses is dramatically reduced, that can have negative effect on PAW efficiency.

Relationship (9), obtained in this work, sets in algebraic form a connection between the frequency of passing welding current pulses $f$ and parameters of welding circuit $R_{\mathrm{w}}$ and $L_{*}$. This relationship using known parameters $R_{\mathrm{w}}$ and $L_{*}$ allows sufficiently easy evaluating the upper boundary of pass band of specific welding circuit, inside which a necessary amplitude of welding current pulses is provided. Obviously, that relationship (9) provides a possibility to solve an inverse problem, i.e. to determine the boundary of allowed values of inductance of welding circuit $L_{*}$ on preliminary selected frequency of pulse passing $f$ and $R_{\mathrm{w}}$ known value.

1. Paton, B.E., Potapievsky, A.G., Podola, N.V. (1964) Consumable electrode pulsed arc welding with programmable control of process. Avtomatich. Svarka, 1, 1-6.

2. Amin, M. (1983) Pulse current parameters for arc stability and controlled metal transfer in arc welding. Welding J., 5, 272-278.

3. Matsunawa, A., Yamamoto, G., Hiramoto, S. (1984) Pulsed arc welding. J. of JWS, 53(6), 20-28.

4. Shejko, P.P., Pavshuk, V.M. (1992) Power source for consumable electrode pulsed-arc welding with smooth control of parameters. Avtomatich. Svarka, 6, 44-46.

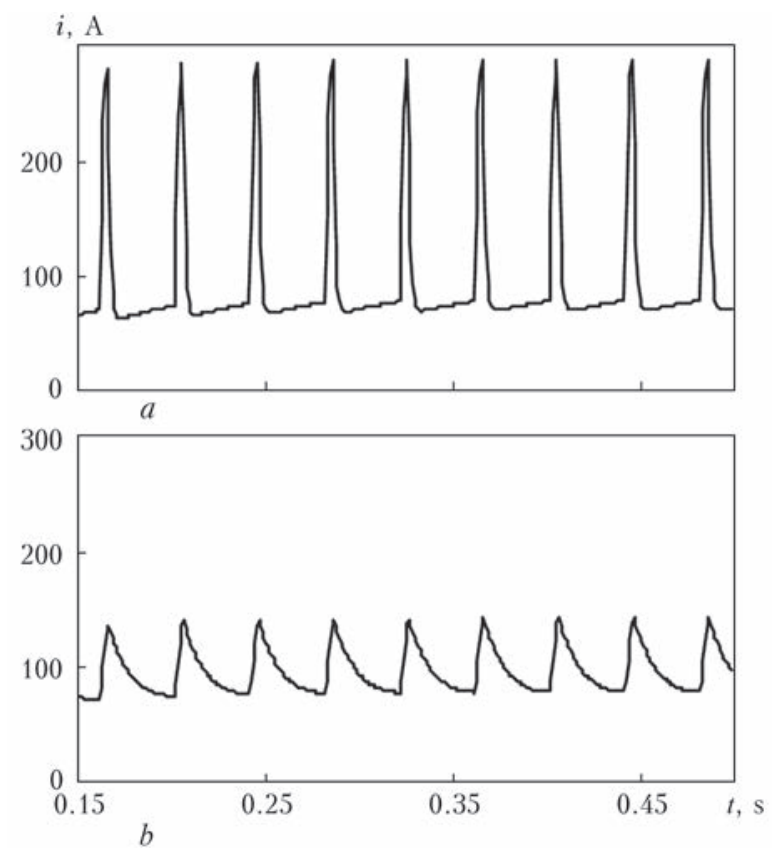

Figure 5. Pulses of welding current at $L_{*}^{\prime}=0.05(a)$ and 0.5 (b) $\mathrm{mH}$

5. Saraev, Yu.N. (1994) Pulsed technological processes of welding and surfacing. Novosibirsk: Nauka.

6. Voropaj, N.M., Ilyushenko, V.M., Lankin, Yu.N. (1999) Specifics of pulsed arc welding with synergic control of parameters (Review). Avtomatich. Svarka, 6, 26-32.

7. Sudnik, V.A., Ivanov, A.V., Diltey, U. (2000) Mathematical model of heat source in shielded metal-arc welding. Pt 2: Pulsed process. Svarochn. Proizvodstvo, 9, 9-15.

8. Saraev, Yu.N. (2002) Adaptive pulsed arc mechanized welding in construction of main pipelines. Ibid., 1, 4-11.

9. Paton, B.E., Shejko, P.P., Zhernosekov, A.M. et al. (2003) Stabilization of the process of consumable electrode pulse-arc welding. The Paton Welding J., 8, 2-5.

10. Dyurgerov, N.G., Sagirov, D.Kh. (2004) Determination of properties in pulsed welding processes. Svarochn. Proizvodstvo, 4, 14-18.

11. Nong, H., Ueyama, T. (2004) Solutions to problems of tiny spatter and arc pulsed MIG welding. Q. J. of JWS, 22(2), 249-247.

12. Tsybulkin, G.A. (2005) Influence of frequency properties of the welding circuit on current parameters in pulsed-arc welding processes. The Paton Welding J., 10, 9-13.

13. Knyazkov, A.F., Krampit, N.Yu., Krampit, A.G. et al. (2005) Study of the process of electrode metal transfer in pulsed supply of welding arc. Tekhnologiya Metallov, 7, 18-21.

14. Krampit, N.Yu., Krampit, A.G. (2014) Study of process of consumable electrode pulsed-arc $\mathrm{CO}_{2}$-shielded welding. Vestnik MGTU im. N.E. Baumana. Series Mashinostroenie, 5, 106-111.

15. Dyurgerov, N.G., Lenivkin, V.A. (2015) Technological stability of consumable electrode pulsed-arc welding. Svarochn. Proizvodstvo, 2, 3-7.

16. Tsybulkin, G.A. (2014) Adaptive control in arc welding. Kiev: Stal.

17. Gutnikov, V.S. (1990) Filtration of measuring signals. Leningrad: Energoatomizdat.

18. Makarov, I.M., Mensky, B.M. (1977) Linear automatic systems (elements of theory, methods of calculation and reference material). Moscow: Mashinostroenie.

19. Leskov, G.I. (1970) Electric welding arc. Moscow: Mashinostroenie.

Received 15.03.2016 